\title{
Administrative level, city tier, and air quality: contextual determinants of hukou conversion for migrants in China
}

\author{
Chenglong Wang ${ }^{1}$, Jianfa Shen ${ }^{*}$ (D) and Ye Liu²
}

\begin{abstract}
Hukou reform and relevant policies are being implemented in current China, but the response of migrants to hukou conversion in destinations falls short of expectation. It is significant to understand how contextual factors in destination cities affect migrants' willingness of hukou conversion. Considering administrative dimension, socioeconomic dimension, and environmental dimension, this study focuses on migrants with settlement intention and examines the impact of administrative level, city tier, and air quality on their willingness of hukou conversion, using questionnaire data collected in 334 cities in 2017. It is found that migrants with settlement intention have a strong incentive to obtain local hukou in destination cities with high administrative levels and city tiers in the northeast, east, and middle China. This effect is increasingly significant for destinations from southwest to northeast China. While in cities with lower city tiers, migrants with settlement intention are less willing to obtain local hukou in the destination. Air quality has a limited impact on migrants' willingness of hukou conversion. But the role of air quality varies among different regions. These findings support that both environmental protection and economic development are important to promote urbanization in China.
\end{abstract}

Keywords: Administrative level, City tier, PM 2.5, Hukou conversion, Settlement intention, Internal migration

\section{Introduction}

During the last 40 years, economic and institutional reforms provide a solid foundation for rapid urbanization in China (Shen, 2018; Zhang \& Sun, 2019). Both statesponsored and spontaneous urbanization involves huge internal migration (Shen, 2006, 2018). Meanwhile, the existence of the household registration (hukou) system creates a formidable and persistent barrier for the migration process and settlement of migrants in the destination (Guo \& Iredale, 2004; Hao \& Tang, 2015; Liu \& $\mathrm{Xu}, 2017$; Shen, 2002; Zhu \& Chen, 2010). Semiurbanization has been a serious issue in urban China (Liu, Cao, Liu, \& Liu, 2016; Wu, Zhang, Xu, \& Li, 2016). It refers to a transitional state in the process of

\footnotetext{
* Correspondence: jianfa@cuhk.edu.hk

'Department of Geography and Resource Management, The Chinese

University of Hong Kong, Shatin, NT, Hong Kong, China

Full list of author information is available at the end of the article
}

urbanization that some rural migrants do not complete their transformation to become urban residents with full rights, which implies various degrees of discrimination against rural migrants caused by hukou status in the labor market, education, housing, social security, etc.

To promote urbanization and eliminate the negative effect produced by the hukou system, hukou reform has been implemented in China (Liu, Pan, Liu, Chen, \& Li, 2020). In 2014, the government published Opinions of the State Council on Further Promotion of Reform of the Household Registration System. Although access to local hukou in major cities such as Beijing and Guangzhou is still under tight control, the new policy aims to help around 100 million rural migrants and other residents to obtain urban hukou in their host cities by 2020 . The relaxation of hukou conversion provides a solution for semi-urbanization and protects the interest of migrants in host cities. However, settlement intention and hukou 
conversion are not only policy issues but also decisions made by migrants based on full consideration of individual conditions. Though central and local governments in China attempt to improve the quality of life for migrants in the destination through hukou reform, the response of migrants to hukou conversion falls short of expectations (Chen \& Fan, 2016; Tang \& Hao, 2018).

Tang and Hao (2018) concluded that settlement in a destination involves two separate decisions for migrants in China, which are "to obtain a local urban hukou in the city" and "to reside in the city permanently". For migrants who wish to settle down at the destination in the future, the former indicates the willingness of hukou conversion, while the latter one is interpreted as settlement intention. Previous studies focused on the inconformity between rural migrants with settlement intention and rural migrants with the willingness of hukou conversion (Chen \& Fan, 2016; Hao \& Tang, 2015; Li \& Liu, 2019; Liu \& Wang, 2020; Tang \& Hao, 2018). But few studies considered these two decisions together. Since hukou status is of significantly geographical excludability, migrants without local hukou cannot get the benefits package in the destination. Thus, it is important to understand the willingness of hukou conversion for migrants with settlement intention.

Combining settlement intention and hukou conversion, our study offers nuanced insights into contextual determinants (including administrative dimension, socio-economic dimension, and environmental dimension) of destination cities in shaping the willingness of hukou conversion of migrants with settlement intention. Findings also shed light on geographical variation of contextual determinants on the willingness of hukou conversion for migrants with settlement intention at the city level, which provides possible hints for hukou reform in current China.

\section{Literature review: settlement intention and willingness of hukou conversion}

\subsection{Hukou and its impacts on migrants}

According to the registration place, hukou (household registration system) is divided into urban hukou and rural hukou, which creates a huge challenge for rural migrants to access social welfare in urban society (Chen \& Fan, 2016; Fan, 2007). Apart from the division between urban hukou and rural hukou, there is a large difference between local hukou and non-local hukou caused by regional disparity. For cities in a shortlist of developed areas such as Beijing, Guangzhou, and Shanghai, local hukou is much more valuable.

Hukou is a distinctive institutional factor and regarded as a formidable barrier for internal migration in China (Guo \& Iredale, 2004; Hao \& Tang, 2015; Liu \& Xu, 2017; Shen, 2002; Zhu \& Chen, 2010). Since the early 1980s, China has experienced great migration from rural areas to urban areas. Most rural migrants are not granted permanent hukou in the city and are known as temporary migrants. Compared with their counterparts who have the local hukou, temporary migrants have lower economic and social status. They have limited access to employment opportunities and social welfare, and their children are struggling to get into schools in the destination (Fan, 2001; Goodburn, 2009; Guo \& Iredale, 2004; Liu et al., 2020; Shen, 2002; Zhu \& Lin, 2014)

In megacities, migrants with local hukou have a better performance in integration into the city, and their income level tends to be higher than those without local hukou (Wang \& Fan, 2012). During 1990 and 2000, the gap between permanent migrants and temporary migrants was widened in most aspects (Sun \& Fan, 2011; Zhu, 2007). According to a national sampling survey in 2002, the gap of the annual income between urban residents and temporary migrants was as large as 1.3 times (Démurger, Gurgand, Li, \& Yue, 2009). In terms of human capital attributes, mobility resources, and labor market entry, temporary migrants are at the bottom of the social hierarchy compared with migrants with local hukou and natives (Fan, 2002).

\subsection{Settlement intention and willingness of hukou conversion}

Hukou status greatly influences migrants' performance in the labor market. Since employment opportunities and income level are closely associated with individuals' educational attainment, Fu and Ren (2010) argued that hukou status affects labor-market return mainly through its influence on peoples' return to education. Age, marital status, educational attainment, landholdings in hometown, homestead in hometown, the level of socioeconomic development in the destination, and city size all contribute to migrants' decision on hukou conversion in the destination (Gu, Jie, Li, \& Shen, 2020; Hao \& Tang, 2015; Lao \& $\mathrm{Gu}, 2020$; Li \& Liu, 2019).

Similarly, migrants' settlement intention is determined by numerous factors. Age, marital status, educational attainment, and working experience play important roles in migrants' decision to stay or leave (Détang-Dessendre, Goffette-Nagot, \& Piguet, 2008; Khoo, Hugo, \& McDonald, 2008; Roberts, 2002; Zhu \& Chen, 2010). Employment opportunities and income level in destinations are also considerations in migrants' final decisions (Fan, 2011; Khoo et al., 2008; Zhu, 2007). For rural migrants with arable land in the hometown, income from crops pulls them back to origins and the arable land has negative impacts on their settlement in the destination (Fan, 2011; Zhu, 2007).

In recent years, the inconformity between settlement intention and willingness of hukou conversion of internal migrants in China has aroused much academic 
attention. It is argued that rural migrants' settlement intention is easily influenced by their employment performance in the labor market and quality of life in the host city (Fan, 2011; Khoo et al., 2008; Tang \& Hao, 2018). By contrast, hukou conversion tends to be a tradeoff between rural and urban benefits related to respective hukou status (Li \& Liu, 2019; Tang \& Hao, 2018). Since rural migrants are more likely to engage in unstable jobs in the destination (King, 2012; Massey et al., 1993), landholding in hometown, which could provide security and reduce risk during their migration life, is an important determinant of hukou conversion (Chen \& Fan, 2016; Hao \& Tang, 2015). The decline in the competitive advantage of urban hukou is another reason that rural migrants are hesitant about hukou conversion (Chen \& Fan, 2016).

In terms of the contextual factors, there is a significant difference in preferred destinations between rural migrants with the willingness of hukou conversion and those with settlement intention. Large cities are top destinations for rural migrants with a high willingness of hukou conversion while small and medium cities are popular for rural migrants with settlement intention (Chen \& Fan, 2016; Li \& Liu, 2019; Liu \& Wang, 2020).

\subsection{Contextual determinants of destination cities in hukou conversion}

This paper pays special attention to the roles of contextual determinants of destination cities in hukou conversion of migrants with settlement intention. Contextual factors in the destination and their difference among cities contribute to the spatial distribution of migrants with settlement intention in China. Previous studies have revealed the impact of city size/urban hierarchy measured by population size on migrants' settlement intention (Hao \& Tang, 2018; Liu \& Wang, 2020). However, the city is a complex organism. At the administrative dimension, cities in the higher administrative hierarchy enjoy more policy preferences and financial support from the central government. The benefits of local hukou are closely connected with the administrative level of a city. Thus, migrants' willingness of hukou conversion may be affected by the administrative level of the destination cities.

Additionally, cities with high socio-economic development levels could provide more job opportunities and better quality of life for migrants. Meanwhile, migrants have to face higher living expenses at the destination. Thus, socio-economic development level may also be an important determinant of hukou conversion. However, the roles of administrative level and city tier in migrants' settlement intention or willingness of hukou conversion are largely ignored in the literature.
At the environmental dimension, air pollution, water shortage and pollution, desertification, and soil pollution are the most serious environmental problems in current China (Kan, 2009). Water shortage and pollution, desertification, and soil pollution are usually issues in the rural area and periphery regions in China, while air pollution is of much concern in urban China. As urban areas are the main destinations of migration, this paper focuses on air quality at the environmental dimension. Air quality plays an important role in the migration process. Since air quality is related to people' physical and mental health (Levinson, 2012; Sun, Kahn, \& Zheng, 2017; Zhang, Zhang, \& Chen, 2017), migrants are sensitive to air quality in potential destinations. Air pollution, to some extent, influences their decision on leave or stay in the host city (Chen, Oliva, \& Zhang, 2017; Qin \& Zhu, 2018). Obtaining local hukou means becoming permanent migrants in the destination. Considering health issues, air quality may influence migrants' willingness to hukou conversion.

Based on above discussion, we propose the following two hypotheses which will be assessed holistically based on the results of quantitative analysis in this paper:

\section{Hypothesis 1: Contextual factors including administrative level, city tier, and air quality play important roles in shaping the willingness of hukou conversion for migrants with settlement intention. Hypothesis 2: The impacts of contextual factors on the willingness of hukou conversion for migrants with settlement intention at the city level vary geographically.}

\section{Data and methods}

\subsection{Data description}

The migrants' data are from China Migrants Dynamic Survey (CMDS) 2017. The survey is conducted by the Migrant Population Service Centre, National Health Commission of P.R. China. Interviewees in the survey are migrants who are aged 15-59 and have been in the destination for more than 1 month without local hukou. To select representative samples based on the size of migration and migrants' characteristics in different provinces/ cities, the survey adopted the method of Probability Proportionate to Size Sampling (PPS), which emphasizes stratification, multi-stage and proportional to size in the process of sample selection. PPS is a powerful tool to select samples from different sized subgroups. The larger a subgroup is, the more members in this subgroup would be selected. The total number of interviewees was 170 , 000 in 2017. In this study, the geographical units are prefecture-level regions. To get reliable results, samples with missing data and 7 prefecture-level regions with less than 20 interviewees are excluded. The remaining number of prefecture-level regions (cities) in this study 
is 334 , involving 138,147 migrants. The migrant data are aggregated to the city level and the number of samples in the statistical analysis is 334 . Additionally, the data on annual mean concentration of PM 2.5 are collected from the respective websites of local governments in China.

\subsection{Method}

\subsubsection{Cluster and outlier analyses}

The cluster and outlier analyses identify spatial clusters of features with high or low values and are based on Anselin Local Moran's I (Anselin, 1995). This approach is used to identify the spatial clusters of areas with a high or low willingness of hukou conversion for migrants with settlement intention at the city level. In this study, migrants with settlement intention fall into two groups: those with the willingness of hukou conversion (WH group) and those without the willingness of hukou conversion (WOH group). We use the cluster and outlier analysis tool in ArcGIS 10.6 to find out the highhigh cluster, high-low outlier, low-high outlier, and lowlow cluster for migrants in $\mathrm{WH}$ group and $\mathrm{WOH}$ group respectively. The high-high cluster in this study refers to city clusters with high proportion of relevant migrant group at the local level. The low-low cluster is composed of cities with a low proportion of respective migrant group at the local level. The high-low outlier indicates that cities in the cluster have a larger proportion of migrants in relevant group surrounded by cities with a low value at the local level. By contrast, low-high outlier demonstrates an opposite situation.

\subsubsection{Multiscale geographically weighted regression (MGWR)}

Traditional techniques such as the logistic regression model are powerful in examining the determinants of migrants' settlement intention or willingness of hukou conversion (Gu, Jie, et al., 2020; Hao \& Tang, 2015; Li \& Liu, 2019; Tang \& Hao, 2018; Zhu \& Chen, 2010). However, it fails to capture the geographical attribute of variables when the samples have significant geographical characteristics. Multi-level analyses including the hierarchical linear model and multilevel logistic regression model are useful to understand migrants' settlement intention or willingness of hukou conversion at varying hierarchical levels (Liu, Deng, \& Song, 2018; Liu \& Wang, 2020). But it ignores the geographical relationship among cities/regions.

Due to the difference between local hukou and nonlocal hukou in China, hukou status is of significantly geographical excludability. This research attempts to capture the geographically varying relationships between contextual factors and migrants' willingness to hukou conversion at the city level. Compared with the global regression focusing on spatial homogeneity, MGWR
(Multiple Geographically Weighted Regression) could capture the spatial heterogeneity and improve data fitting (Fotheringham, Yang, \& Kang, 2017; Oshan, Li, Kang, Wolf, \& Fotheringham, 2019), which has been applied to the study of migration pattern and migrants' hukou transfer intention in previous studies $(\mathrm{Gu}, \mathrm{Yu}$, Sachdeva, \& Liu, 2020; Lao \& Gu, 2020). The Traditional Geographically Weighted Regression (GWR) is a spatial regression technique to evaluate a local model of the process and model spatially nonstationary relationships (Fotheringham, Brunsdon, \& Charlton, 2002). However, it assumes that all relationships vary at the same spatial scale, which may cause over-fitting and bias in parameter estimation (Oshan et al., 2019). As an extension of GWR, MGWR makes it possible to model processes at different spatial scales and obtain more reliable results (Fotheringham et al., 2017). Thus, we use the MGWR in this study.

$$
y_{i}=\beta_{\mathrm{o}}\left(u_{i}, v_{i}\right)+\sum_{j=0}^{m} \beta_{b w j}\left(u_{i}, v_{i}\right) x_{i j}+\varepsilon_{i}
$$

(1) is the equation for the MGWR model. In the model, $\mathrm{i}$ represents the observation and is an integer, where $1 \leq \mathrm{i} \leq \mathrm{n} .\left(u_{i}, v_{i}\right)$ indicates the location, which could be expressed as either distance or decimal degrees such as latitude and longitude. In this research, we select the distance (unit: kilometer) in the projected coordinate system to measure the location of cities. $\beta_{0}\left(u_{i}, v_{i}\right)$ is the intercept $\beta_{0}$ at the location $\left(u_{i}, v_{i}\right)$. In this study, SIWH is defined as the proportion of migrants with settlement intention and willingness of hukou conversion in total migrants in the destination city. SIWOH is defined as the proportion of migrants with settlement intention but without the willingness of hukou conversion in total migrants in the destination city. Thus, the dependent variable, $y_{i}$ (SIWH or SIWOH), is the ratio of migrants in WH or WOH group to total migrants in city i. The independent variable, $x_{i j}$. is determinant $\mathrm{j}$ in city i. $\beta_{b w j}$ indicates the bandwidth used for calibration of the jth conditional relationship (Fotheringham et al., 2002). $\varepsilon_{i}$ is the residual. In order to figure out whether there are geographically varying relationships between the dependent variable and independent variables, we adopt the OLS (Ordinary Least Squares) model, GWR model, and MGWR model respectively.

\subsection{Variables and indicator system}

In this study, the dependent variable is SIWH or SIWOH. Settlement intention is measured by migrants' response to the question "Do you intend to settle down in the destination city (more than 5 years)?" Migrants' willingness to hukou conversion is measured by the question "Do you intend to obtain local hukou if you meet the relevant requirements in the destination city?" 
Independent variables are contextual factors of the destination city. In this research, contextual factors of the destination city include three dimensions which are administrative dimension, socio-economic dimension, and environmental dimension. The administrative dimension reflects the potential value of local hukou in destination cities. The socio-economic dimension and environmental dimension are proposed to measure the quality of life and living environment in the destination.

At the administrative dimension, cities in mainland China are classified into 6 groups based on the administrative level, which are provincial level, sub-provincial level, quasi sub-provincial level, prefecture-level, subprefecture level, and county level (Wang, Liu, \& Zhang, 2020; Wang, Liu, Zhang, et al., 2018). A city in a higher administrative hierarchy tends to enjoy more policy preferences and financial support from the central government. The benefits of local hukou are closely related to the administrative level of the city. In this research, the administrative level is set as an ordinal variable. Cities at the provincial level, sub-provincial level, quasi subprovincial level, prefecture-level, sub-prefecture level, and county level are assigned with values of 6, 5, 4, 3, 2, and 1 respectively.

At the socio-economic dimension, the city tier system is a comprehensive indicator to measure the socioeconomic development level and future potential of different cities, which has been widely applied to urban and regional studies in China (Lyu, Liao, \& Huang, 2018; Tsai \& Chiang, 2019; Wu \& Bian, 2018; Zhang, Zhou, \& $\mathrm{Hu}, 2013)$. China's city tier system was firstly proposed by the research team of Yicai Media Group (formerly the China Business Network). Based on big data and user behavior data, cities in mainland China are divided into different tiers according to their performance in business, transportation, urbanism, lifestyle diversity, and development potential. Currently, there are six tiers in the system, which are the first tier, the new first tier, the second tier, the third tier, the fourth tier, and the fifth tier. The first-tier cities include Beijing, Shanghai, Guangzhou, and Shenzhen, which are the most developed areas in China. In this study, the city tier is set as an ordinal variable. Cities in the first tier, the new first tier, the second tier, the third tier, the fourth tier, and the fifth tier are assigned with values of $6,5,4,3,2$, and 1 respectively.

At the environmental dimension, air quality influences people's physical and mental health (Levinson, 2012; Sun et al., 2017; Zhang et al., 2017). Migrants are sensitive to air quality in potential destinations and air pollution, to some extent, influences their decision to leave or stay in the host city (Chen et al., 2017; Qin \& Zhu, 2018). Particulate matter (PM) air pollution especially PM 2.5 (PM $<2.5 \mu \mathrm{m}$ in diameter) has been widely applied in studies related to air pollution (Cai et al., 2017; de Miranda et al., 2012; Wellenius et al., 2012). Thus, we select annual mean concentration of PM 2.5 as the indicator of air quality. The annual mean instead of extreme value in a year is used as annual mean is more stable and migrants are concerned with long-term air-quality instead of extreme condition at a particular time.

Besides, this study includes a set of control variables. Following previous studies (Gu, Jie, et al., 2020; Hao \& Tang, 2015; Lao \& Gu, 2020; Li \& Liu, 2019; Li \& Siu, 1997; Liang \& Ma, 2004; Zhu \& Chen, 2010), age, gender, educational attainment, marital status, migration experience, employment status (wage-employment, selfemployment and entrepreneurship), consideration in hometown, and the attitude of the host city are selected as control variables. To avoid multicollinearity, we select specific categories of control variables, such as age group (15-29 and 30-49), gender (male), hukou status (nonagricultural hukou), marital status (unmarried), migration type (intra-provincial migration), and employment status(wage-employment and self-employment). The indicator system is shown in Table 1.

\section{Results}

\subsection{Model evaluation}

To fully capture the impact of contextual factors on the willingness of hukou conversion for migrants with settlement intention at the city level, this part attempts to find the best model by comparing data fitting and model significance among OLS model, GWR model, and MGWR model. Firstly, we performed the collinearity analysis in the OLS model. As shown in Tables 2 and 3, all values of VIF are less than 10 and all values of tolerance are much larger than 0 . Thus, we can conclude that there is no multicollinearity in the models (Aljandali, 2017, Page 5).

Then GWR and MGWR models are estimated. The diagnostic information includes AIC (Akaike information criterion), AICc (AIC with a correction for small sample sizes), and R-square. As shown in Table 2, the AICc of the OLS model, GWR model, and MGWR model for SIWH are 828.566, 766.961, and 753.072 respectively. There is an improvement of 75.494 in AICc from the OLS model to the MGWR model. The improvement from the GWR model to the MGWR model is 13.889, which indicates that the MGWR model has the best data fitting. Additionally, the R-square of the MGWR model is 0.634, which is larger than those of the OLS model (0.380) and GWR model (0.593). Thus, the MGWR model has better performance in explaining the relationship between the dependent variable (SIWH) and independent variables. Similarly, there are improvements in AICc from the OLS model to the MGWR model and from the GWR model to the MGWR model 


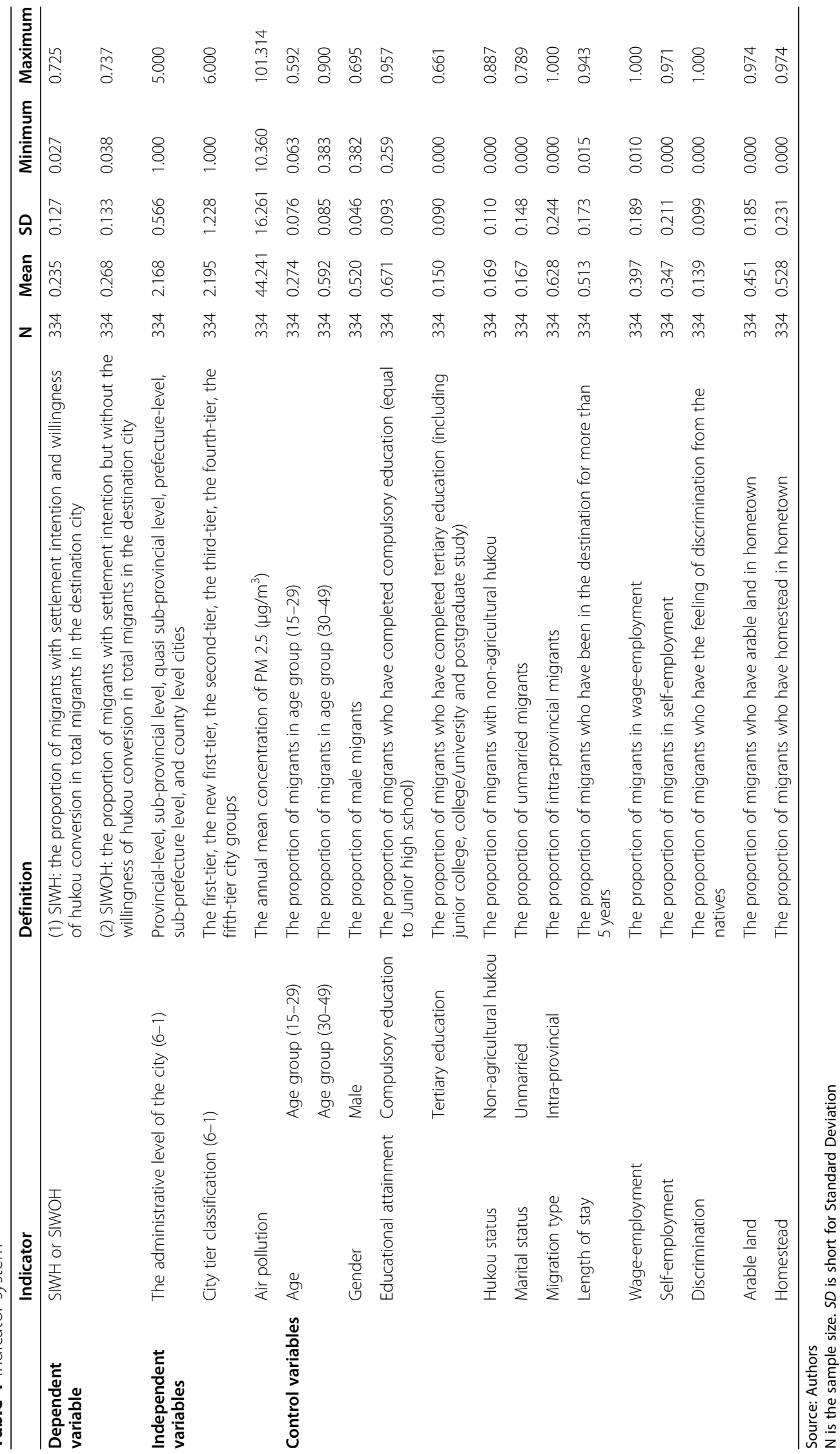


Table 2 Calculation results for SIWH

\begin{tabular}{|c|c|c|c|c|c|c|c|c|c|c|c|}
\hline \multirow{3}{*}{ Variables } & \multicolumn{3}{|c|}{ OLS model } & \multicolumn{4}{|c|}{ GWR model } & \multicolumn{4}{|c|}{ MGWR model } \\
\hline & \multirow[t]{2}{*}{$\bar{\beta}$} & \multicolumn{2}{|c|}{ Collinearity Statistics } & \multirow[t]{2}{*}{$\beta$ (Mean) } & \multirow[t]{2}{*}{ SD } & \multirow[t]{2}{*}{$\beta$ (Min) } & \multirow[t]{2}{*}{$\beta$ (Max) } & \multirow[t]{2}{*}{$\beta$ (Mean) } & \multirow[t]{2}{*}{ SD } & \multirow[t]{2}{*}{$\beta$ (Min) } & \multirow[t]{2}{*}{$\beta$ (Max) } \\
\hline & & Tolerance & VIF & & & & & & & & \\
\hline Administrative level & $0.061^{\mathrm{a}}$ & 0.536 & 1.867 & 0.227 & 0.069 & 0.109 & 0.400 & 0.202 & 0.060 & 0.088 & 0.274 \\
\hline City tier & -0.002 & 0.372 & 2.691 & 0.063 & 0.109 & -0.403 & 0.266 & 0.132 & 0.024 & 0.026 & 0.166 \\
\hline PM 2.5 & $0.001^{b}$ & 0.788 & 1.268 & 0.007 & 0.135 & -0.280 & 0.447 & -0.110 & 0.136 & -0.493 & 0.284 \\
\hline Age group (15-29) & $0.316^{\mathrm{b}}$ & 0.312 & 3.205 & 0.091 & 0.163 & -0.174 & 0.523 & 0.115 & 0.010 & 0.097 & 0.147 \\
\hline Age group (30-49) & 0.041 & 0.370 & 2.703 & -0.046 & 0.093 & -0.243 & 0.132 & -0.032 & 0.093 & -0.204 & 0.149 \\
\hline Male & -0.259 & 0.762 & 1.312 & -0.086 & 0.019 & -0.122 & -0.030 & -0.068 & 0.008 & -0.084 & -0.041 \\
\hline Compulsory education & $-0.405^{a}$ & 0.523 & 1.914 & -0.154 & 0.158 & -0.524 & 0.101 & -0.255 & 0.053 & -0.430 & -0.187 \\
\hline Tertiary education & -0.179 & 0.372 & 2.690 & -0.007 & 0.142 & -0.275 & 0.227 & -0.063 & 0.053 & -0.171 & 0.005 \\
\hline Non-agricultural hukou & 0.096 & 0.470 & 2.130 & 0.027 & 0.070 & -0.138 & 0.180 & 0.050 & 0.053 & -0.022 & 0.160 \\
\hline Unmarried & -0.029 & 0.836 & 1.196 & -0.012 & 0.063 & -0.266 & 0.128 & 0.012 & 0.072 & -0.209 & 0.245 \\
\hline Intra-provincial migration & -0.019 & 0.596 & 1.679 & 0.026 & 0.053 & -0.131 & 0.127 & 0.063 & 0.021 & 0.019 & 0.114 \\
\hline Length of stay & $0.169^{a}$ & 0.567 & 1.762 & 0.190 & 0.070 & 0.110 & 0.444 & 0.143 & 0.075 & 0.078 & 0.446 \\
\hline Wage-employment & -0.076 & 0.186 & 5.387 & -0.069 & 0.052 & -0.156 & 0.160 & -0.014 & 0.005 & -0.028 & -0.006 \\
\hline Self-employment & $-0.155^{b}$ & 0.191 & 5.233 & -0.186 & 0.062 & -0.312 & -0.007 & -0.085 & 0.005 & -0.091 & -0.067 \\
\hline Discrimination & -0.056 & 0.753 & 1.329 & -0.065 & 0.064 & -0.217 & 0.026 & -0.074 & 0.013 & -0.110 & -0.052 \\
\hline Arable land & -0.076 & 0.351 & 2.851 & -0.030 & 0.131 & -0.257 & 0.298 & 0.034 & 0.011 & 0.005 & 0.052 \\
\hline Homestead & -0.021 & 0.230 & 4.339 & -0.112 & 0.180 & -0.602 & 0.097 & -0.210 & 0.106 & -0.422 & -0.002 \\
\hline \multicolumn{12}{|l|}{ Goodness-of-fit } \\
\hline $\mathrm{AlC}$ & 824.145 & & & 748.533 & & & & 728.242 & & & \\
\hline $\mathrm{AlCC}$ & 828.566 & & & 766.961 & & & & 753.072 & & & \\
\hline R-square & 0.380 & & & 0.593 & & & & 0.634 & & & \\
\hline Adjusted R-square & 0.347 & & & 0.522 & & & & 0.558 & & & \\
\hline
\end{tabular}

Source: Author

SIWH represents the proportion of migrants with intention of settlement and hukou conversion. $\beta$ is the estimate of relevant variable. SD is short for Standard Deviation. ${ }^{\mathrm{a}}$ and ${ }^{\mathrm{b}}$ indicate that the relevant determinants pass the significance test at 0.01 level and 0.05 level respectively

for SIWOH, which are 34.540 and 20.300 respectively (Table 3). R-square of the MGWR model (0.621) is larger than those of the OLS model (0.480) and GWR model (0.578). The diagnostic information of OLS, GWR, and MGWR models in Tables 2 and 3 show that the MGWR model should be adopted for both the SIWH and SIWOH.

\subsection{Spatial distribution of migrants in WH group and WOH group}

According to the CMDS in 2017, the proportion of migrants with settlement intention is around $52.3 \%$ in China. There is inconformity in the willingness of hukou conversion among migrants with settlement intention. $60.2 \%$ of migrants with settlement intention would like to obtain local hukou in the host city while the remaining $39.8 \%$ would like to settle in the destination without hukou conversion.

Figure 1 illustrates the distribution of migrants in the WH group and WOH group at the city level respectively. Beijing-Tianjin region, Yangtze River Delta region, and Pearl River Delta region are top destinations in China. As the core cities of the Beijing-Tianjin region and Yangtze River Delta region, Beijing and Shanghai have the highest proportion of migrants with settlement intention and willingness of hukou conversion (Fig. 1a). While the proportions of migrants with settlement intention but without the willingness of hukou conversion in Beijing, Shanghai, and Guangzhou are in the lowest group "3.85\%-13.90\%" (Fig. 1b).

Based on the cluster and outlier analysis, 334 cities fall into five groups including the high-high cluster, low-low cluster, high-low outlier, low-high outlier, and insignificant group (Fig. 2). In Fig. 2a (WH group), cities in the high-high cluster are those with a high proportion of migrants with settlement intention and willingness of hukou conversion. The low-low cluster refers to the city group with a low proportion of migrants with settlement intention and willingness of hukou conversion. Cities in high-low outlier or low-high outlier are those that have very different values, high or low, in the proportion of migrants with settlement intention and willingness of 
Table 3 Calculation results for SIWOH

\begin{tabular}{|c|c|c|c|c|c|c|c|c|c|c|c|}
\hline \multirow{3}{*}{ Variables } & \multicolumn{3}{|c|}{ OLS model } & \multicolumn{4}{|c|}{ GWR model } & \multicolumn{4}{|c|}{ MGWR model } \\
\hline & \multirow[t]{2}{*}{$\beta$} & \multicolumn{2}{|c|}{ Collinearity Statistics } & \multirow[t]{2}{*}{$\beta$ (Mean) } & \multirow[t]{2}{*}{ SD } & \multirow[t]{2}{*}{$\beta$ (Min) } & \multirow[t]{2}{*}{$\beta$ (Max) } & \multirow[t]{2}{*}{$\beta$ (Mean) } & \multirow[t]{2}{*}{ SD } & \multirow[t]{2}{*}{$\beta$ (Min) } & \multirow[t]{2}{*}{$\beta$ (Max) } \\
\hline & & Tolerance & VIF & & & & & & & & \\
\hline Administrative level & $-0.046^{a}$ & 0.536 & 1.867 & -0.179 & 0.034 & -0.226 & -0.084 & -0.121 & 0.044 & -0.175 & -0.012 \\
\hline City tier & 0.005 & 0.372 & 2.691 & 0.070 & 0.033 & -0.026 & 0.130 & -0.025 & 0.007 & -0.032 & 0.003 \\
\hline PM 2.5 & -0.001 & 0.788 & 1.268 & -0.107 & 0.060 & -0.187 & 0.018 & -0.068 & 0.009 & -0.093 & -0.050 \\
\hline Age group (15-29) & $-0.281^{\mathrm{b}}$ & 0.312 & 3.205 & -0.153 & 0.034 & -0.225 & -0.104 & -0.157 & 0.007 & -0.167 & -0.127 \\
\hline Age group (30-49) & -0.002 & 0.370 & 2.703 & 0.019 & 0.056 & -0.093 & 0.112 & -0.043 & 0.006 & -0.056 & -0.027 \\
\hline Male & -0.219 & 0.762 & 1.312 & -0.073 & 0.019 & -0.131 & -0.047 & -0.084 & 0.008 & -0.095 & -0.058 \\
\hline Compulsory education & $0.504^{\mathrm{a}}$ & 0.523 & 1.914 & 0.353 & 0.086 & 0.166 & 0.518 & 0.355 & 0.019 & 0.301 & 0.390 \\
\hline Tertiary education & $0.633^{\mathrm{a}}$ & 0.372 & 2.690 & 0.382 & 0.153 & 0.095 & 0.695 & 0.389 & 0.070 & 0.266 & 0.511 \\
\hline Non-agricultural hukou & $-0.22^{b}$ & 0.470 & 2.130 & -0.113 & 0.103 & -0.336 & 0.113 & -0.073 & 0.047 & -0.196 & -0.007 \\
\hline Unmarried & -0.008 & 0.836 & 1.196 & -0.012 & 0.060 & -0.169 & 0.065 & -0.048 & 0.105 & -0.319 & 0.064 \\
\hline Intra-provincial migration & $0.14^{\mathrm{a}}$ & 0.596 & 1.679 & 0.279 & 0.041 & 0.202 & 0.346 & 0.290 & 0.020 & 0.199 & 0.305 \\
\hline Length of stay & 0.018 & 0.567 & 1.762 & 0.022 & 0.023 & -0.021 & 0.073 & 0.024 & 0.003 & 0.014 & 0.032 \\
\hline Wage-employment & $-0.167^{b}$ & 0.186 & 5.387 & -0.336 & 0.081 & -0.478 & -0.187 & -0.367 & 0.006 & -0.373 & -0.345 \\
\hline Self-employment & $-0.153^{a}$ & 0.191 & 5.233 & -0.335 & 0.084 & -0.474 & -0.169 & -0.287 & 0.003 & -0.292 & -0.280 \\
\hline Discrimination & 0.072 & 0.753 & 1.329 & 0.066 & 0.082 & -0.103 & 0.222 & 0.107 & 0.177 & -0.222 & 0.453 \\
\hline Arable land & $0.26^{\mathrm{a}}$ & 0.351 & 2.851 & 0.405 & 0.090 & 0.228 & 0.580 & 0.454 & 0.011 & 0.413 & 0.467 \\
\hline Homestead & $-0.258^{a}$ & 0.230 & 4.339 & -0.520 & 0.138 & -0.766 & -0.270 & -0.538 & 0.011 & -0.555 & -0.508 \\
\hline \multicolumn{12}{|l|}{ Goodness-of-fit } \\
\hline $\mathrm{AlC}$ & 765.414 & & & 743.352 & & & & 719.137 & & & \\
\hline $\mathrm{AlCC}$ & 769.834 & & & 755.594 & & & & 735.294 & & & \\
\hline R-square & 0.480 & & & 0.578 & & & & 0.621 & & & \\
\hline Adjusted R-square & 0.452 & & & 0.519 & & & & 0.559 & & & \\
\hline
\end{tabular}

Source: Author

SIWOH represents the proportion of migrants with settlement intention but without the willingness of hukou conversion. $\beta$ is the estimate of relevant variable. $S D$ is short for Standard Deviation. ${ }^{\mathrm{a}}$ and ${ }^{\mathrm{b}}$ indicate that the relevant determinants pass the significance test at 0.01 level and 0.05 level respectively

hukou conversion from their neighboring cities. In Fig. 2b (WOH group), cities in the high-high cluster are those with a high proportion of migrants with settlement intention but without the willingness of hukou conversion. The low-low cluster refers to the city group with a low proportion of migrants with settlement intention but without the willingness of hukou conversion. Cities in high-low outlier or low-high outlier are those that have very different values in the proportion of migrants with settlement intention but without the willingness of hukou conversion from their neighboring cities.

As shown in Fig. 2a, the high-high clusters of the WH group are mainly located in the Beijing-Tianjin-Hebei region, Circum-Bohai-Sea region, Xinjiang, and Hainan province. These areas are clusters with a high proportion of migrants who would like to obtain local hukou. The high-high clusters could be divided into two categories, which are "cities around the capital Beijing" and "the most remote cities in China" (Fig. 2a). But the low-low clusters of the WH group are mainly situated in central China. For the migrants with settlement intention but without the willingness of hukou conversion (WOH group), cities in the high-high clusters are mainly located in northeast China, Shandong province, Anhui province, Henan province, northern Jiangsu province, and Chongqing (Fig. 2b). But cities in low-low clusters are mainly located in southeast and western China.

The spatial pattern illustrated in Figs. 1 and 2 is the result of the combined effect of all control variables and independent variables in Table 1 . This paper pays special attention to the role of contextual determinants and attempts to examine the geographically varying relationship between the contextual factors and the proportion of migrants in the $\mathrm{WH} / \mathrm{WOH}$ group at the city level.

\subsection{Findings}

Table 4 is the summary of significant determinants in models for SIWH and SIWOH based on MGWR. "+" indicates a positive effect of the respective determinant on SIWH or SIWOH in the destination at the city level; "-" indicates a negative effect of the influencing factor on SIWH or SIWOH at the city level; "\#” represents that 


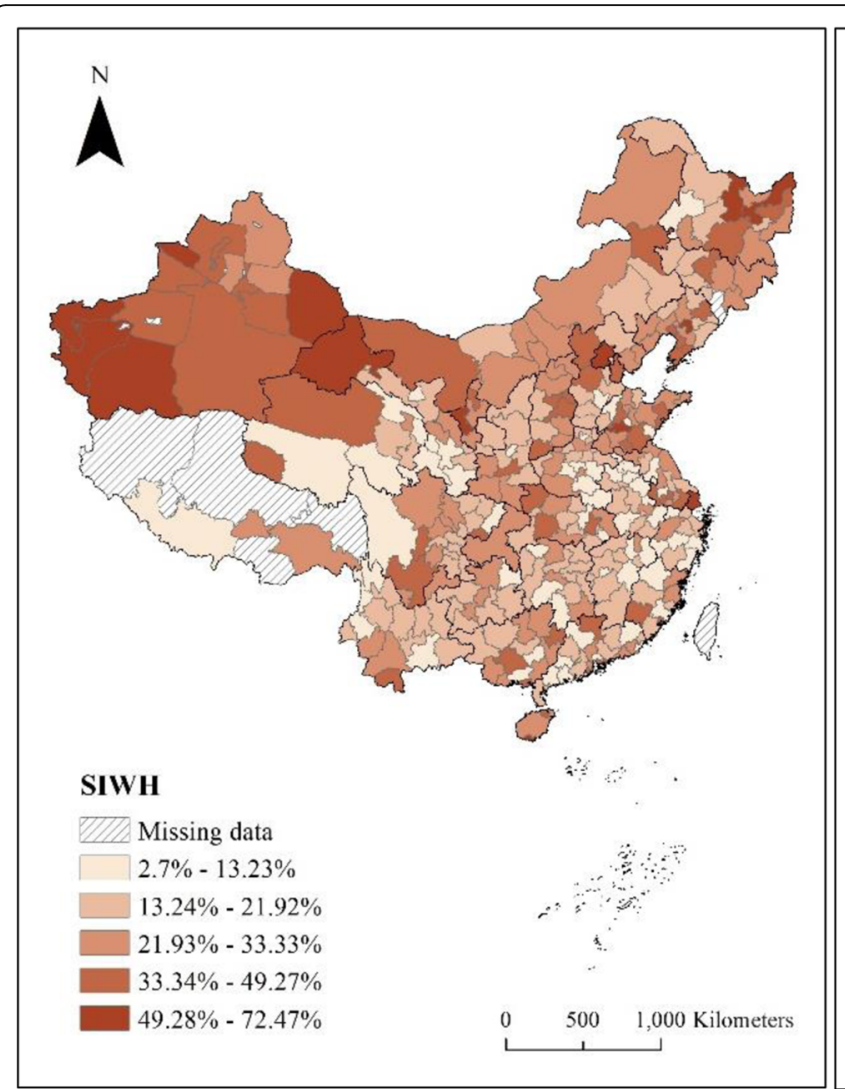

\section{a. WH}

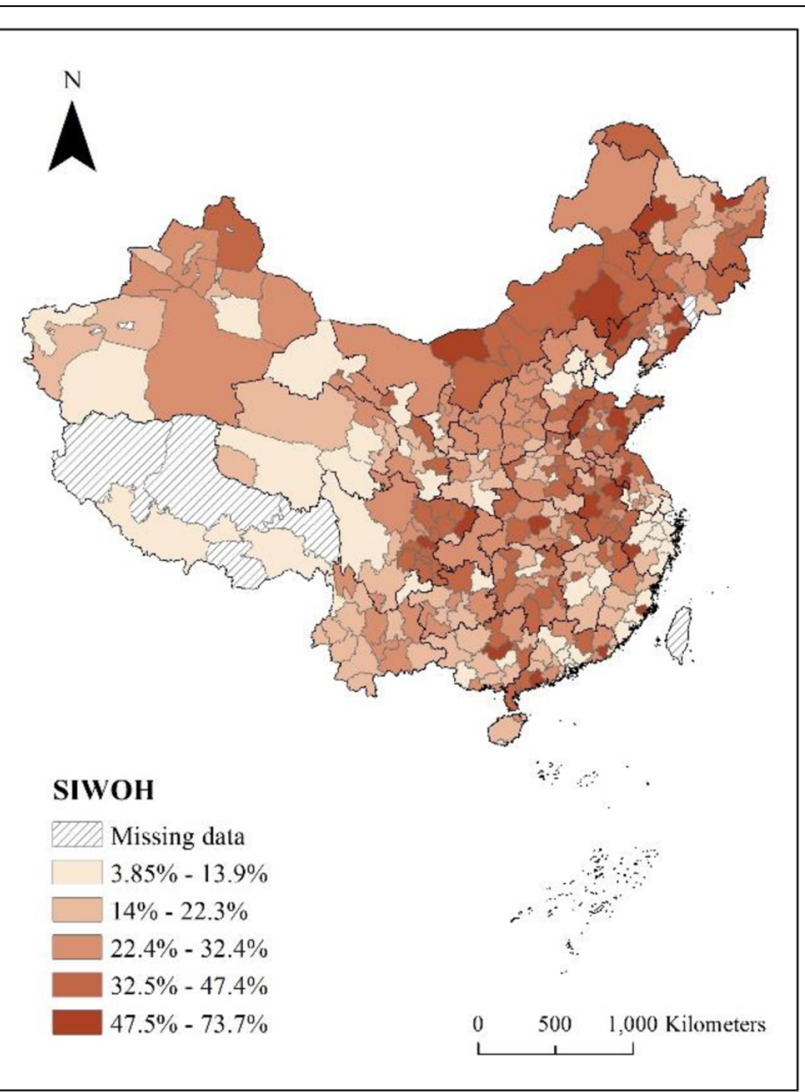

b. WOH

Fig. 1 The proportion of the respective migrants in the destination at the city level in 2017 (\%). Notes: "WH" is short for the migrants with settlement intention and willingness of hukou conversion. "WOH" is short for the migrants having settlement intention but without the willingness of hukou conversion

there are both positive and negative effects caused by the respective influencing factor in different destinations. Additionally, "+" "-"/ "\#" indicates that the relevant determinant passes the significance test at 0.05 level in some or all destinations. Those without the symbol ("+") "-" "\#") indicate that the relevant determinants fail to pass the significance test at 0.05 level in every city.

For SIWH, demographic characteristics (including educational attainment, hukou status, and marital status), length of stay in the destination, homestead, and contextual factors are significant determinants. While for SIWOH, significant determinants include all demographic characteristics, migration experience, employment status, the attitude of the host city, consideration in hometown, and contextual factors. Thus, the first hypothesis is verified that contextual factors including administrative level, city tier, and air quality play important roles in shaping the willingness of hukou conversion for migrants with settlement intention. Additionally, compared with migrants with settlement intention and willingness of hukou conversion, those who have settlement intention but without the willingness of hukou conversion tend to have more considerations.
At the administrative dimension, the administrative level of the destination city has a positive impact on the proportion of migrants with settlement intention and willingness of hukou conversion in the destination (Fig. 3a). The higher the administrative level of the host city is, the larger the proportion of migrants who would like to obtain local hukou and settle in the destination would be. This is significant in most cities except those in western China. In China, the value of local hukou is related to cities' administrative level. Since cities in the higher administrative hierarchy gain more preferential policies and financial support from the central government, they can provide better social welfare and security for residents. Therefore, migrants with settlement intention have a strong willingness to obtain local hukou in cities with a high administrative level. However, most cities in western China are less advanced and provide limited job opportunities and relatively lower salaries for potential migrants. Even though cities with higher administrative levels could gain more financial support from the central government, it is impossible for them to significantly increase jobs and income level in a short 


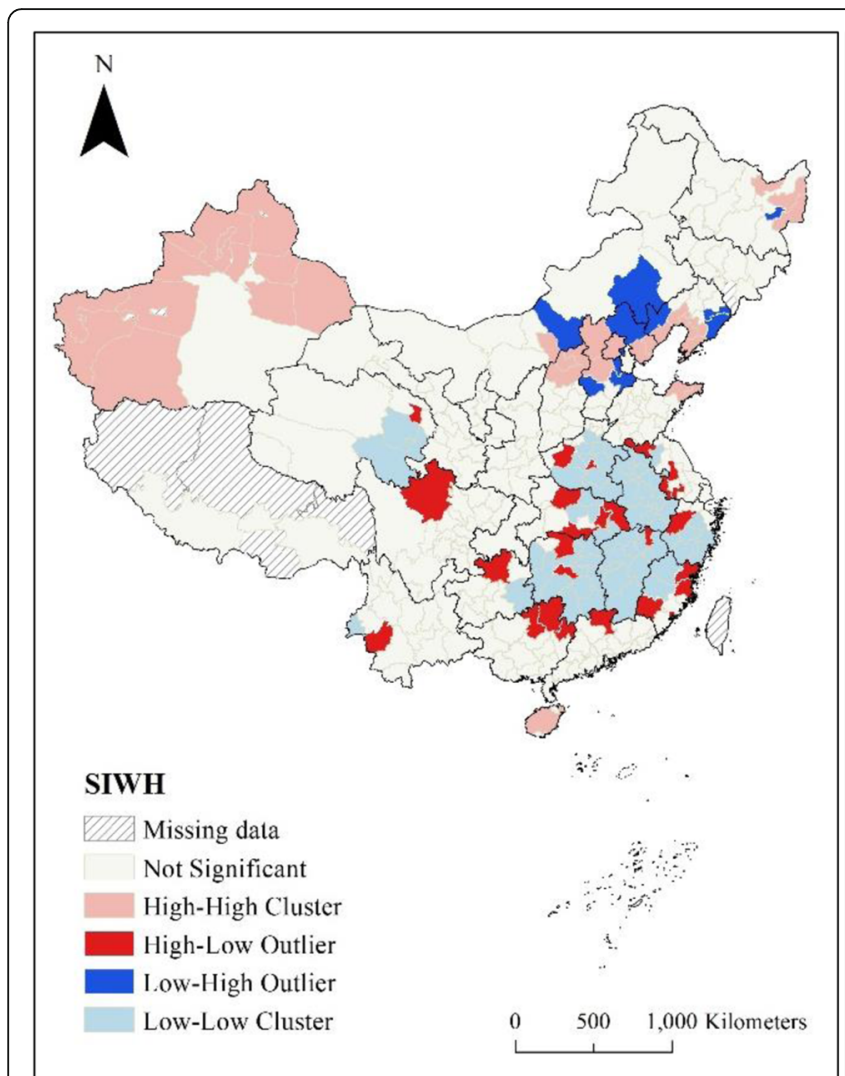

a. Spatial pattern of WH

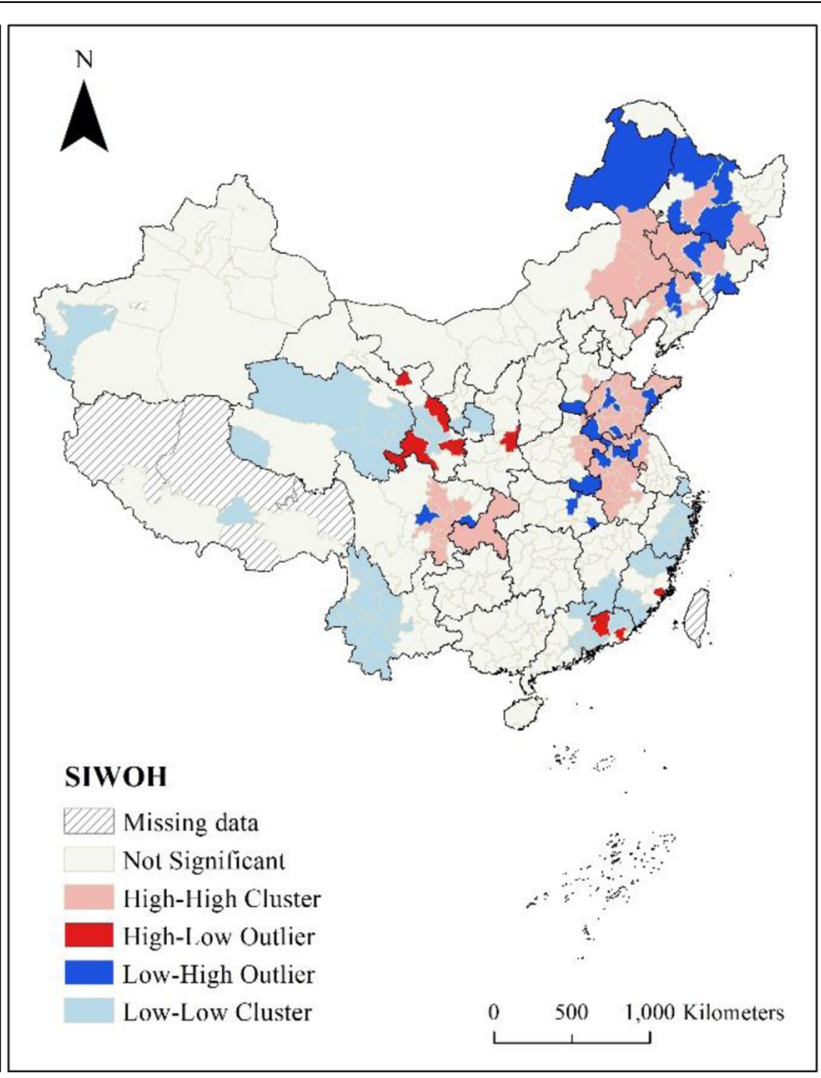

b. Spatial pattern of WOH

Fig. 2 Spatial distribution of migrants at the city level in 2017. Notes: "WH" is short for the migrants with settlement intention and willingness of

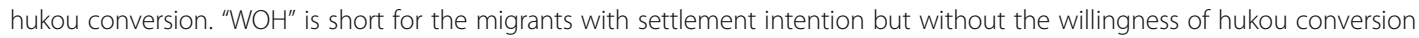

time. Thus, the role of the administrative level in the willingness of hukou conversion is weak in western China. As shown in Fig. 3b, the administrative level of cities in Xinjiang, Qinghai, Tibet, Sichuan, Chongqing, Guizhou, and Yunnan fail to pass the significance test at 0.05 level. For migrants with settlement intention but without the willingness of hukou conversion, administrative hierarchy is influential in cities in the northeast, east, and middle China (Fig. 3d). Since all coefficients are negative (Fig. 3c), it indicates that a city with a higher administrative level has a smaller proportion of migrants who have with settlement intention but without the willingness of hukou conversion. Thus, for migrants with settlement intention in most cities in the northeast, east, and middle China, the administrative level has a positive impact on their willingness to hukou conversion. In other words, cities with higher administrative levels attract more migrants to obtain local hukou in the destination. This trend is strengthened from the west to the east of China.

At the socio-economic dimension, city tier is a comprehensive indicator of the socio-economic development level of a destination city. It is a significant determinant for SIWH (Table 4). As shown in Fig. 4, the city tier has a similar impact as that of the administrative level on the proportion of migrants with settlement intention and willingness of hukou conversion at the city level. All coefficients are positive. There is a decreasing trend in the value of coefficients from eastern to western China (Fig. 4a). Besides, cities with significant coefficients of city tier have similar distribution as that for administrative level shown in Fig. 3b, which mainly located in the northeast, eastern, and middle China. It indicates that migrants with settlement intention have a stronger willingness to obtain local hukou when the destination has a higher city tier. This phenomenon is increasingly significant from western to eastern China.

Generally, cities with high city tiers gain priority in socio-economic development. They provide more job opportunities, higher salary and quality of life for residents. Therefore, becoming a permanent migrant is attractive to a migrant with settlement intention in these cities. In other words, city tier contributes positively to the willingness of hukou conversion for migrants with settlement intention in the destination. However, all first-tier cities and most new first-tier and second-tier 
Table 4 The significant determinants models for SIWH and SIWOH based on MGWR

\begin{tabular}{|c|c|c|c|}
\hline Groups & Variable & SIWH & SIWOH \\
\hline \multicolumn{4}{|l|}{ Demographic characteristics } \\
\hline \multirow[t]{2}{*}{ Age } & Age group (15-29) & & - \\
\hline & Age group (30-49) & & \\
\hline Gender & Male & & - \\
\hline \multirow[t]{2}{*}{ Educational attainment } & Compulsory education & - & + \\
\hline & Tertiary education & & + \\
\hline Hukou status & Non-agricultural hukou & - & - \\
\hline Marital status & Unmarried & \# & \# \\
\hline \multirow[t]{2}{*}{ Migration experience } & Intra-provincial migration & & + \\
\hline & Length of stay & + & \\
\hline \multirow[t]{2}{*}{ Employment status } & Wage-employment & & - \\
\hline & Self-employment & & - \\
\hline $\begin{array}{l}\text { The attitude of the } \\
\text { host society }\end{array}$ & Discrimination & & $\#$ \\
\hline \multirow{2}{*}{$\begin{array}{l}\text { Consideration in } \\
\text { hometown }\end{array}$} & Arable land & & + \\
\hline & Homestead & - & - \\
\hline \multirow[t]{3}{*}{ Contextual factors } & Administrative level & + & - \\
\hline & City tier & + & \\
\hline & PM 2.5 & \# & \\
\hline
\end{tabular}

Source: Author
However, there is a different relationship between air quality and SIWH in Xinjiang. The lower annual mean concentration of PM 2.5 in the destination contributes to a smaller proportion of migrants with settlement intention and hukou conversion in the destination. Xinjiang is an underdeveloped region in China. Most city-level regions in Xinjiang lack modern industry with a low level of economic development. Therefore, they are unable to provide enough job opportunities for migrants. Understandably, migrants with settlement intention would like to obtain local hukou in a destination with more industries and economic activities where air quality will be negatively influenced.

According to the roles of administrative level, city tier, and PM 2.5 in the willingness of hukou conversion for migrants with settlement intention, it is confirmed that the impacts of contextual factors vary geographically. The second hypothesis is verified that the impacts of contextual factors on the willingness of hukou conversion for migrants with settlement intention at the city level vary geographically.

\section{Conclusion and discussion}

In current China, central and local governments have taken steps to protect the benefits of migrants in destinations by the implementation of hukou reform and relevant policies. However, not all migrants are enthusiastic about obtaining local hukou in the host city. In 2017 , only around $60 \%$ of migrants with settlement intention would like to obtain local hukou in the destination, while $40 \%$ of them prefer to have a long stay in the destination (more than 5 years) without hukou conversion.

This paper considers migrants' settlement intention and willingness of hukou conversion in the same time and examines the roles of contextual factors in the willingness of hukou conversion for migrants with settlement intention. Research results support that contextual factors including administrative level, city tier, and air quality play important roles in shaping the willingness of hukou conversion for migrants with settlement intention. The impacts of these contextual factors vary geographically.

We found that migrants with settlement intention but without the willingness of hukou conversion tend to have more considerations in the destination than those with settlement intention and willingness of hukou conversion. At the city level, the proportion of migrants in the WH group (migrants with settlement intention and willingness of hukou conversion) in the destination is influenced by the administrative level, city tier, and PM 2.5 of the city. While the administrative level is the only significant determinant for migrants in the $\mathrm{WOH}$ group (migrants with settlement intention but without the tion of PM 2.5 in these regions. 


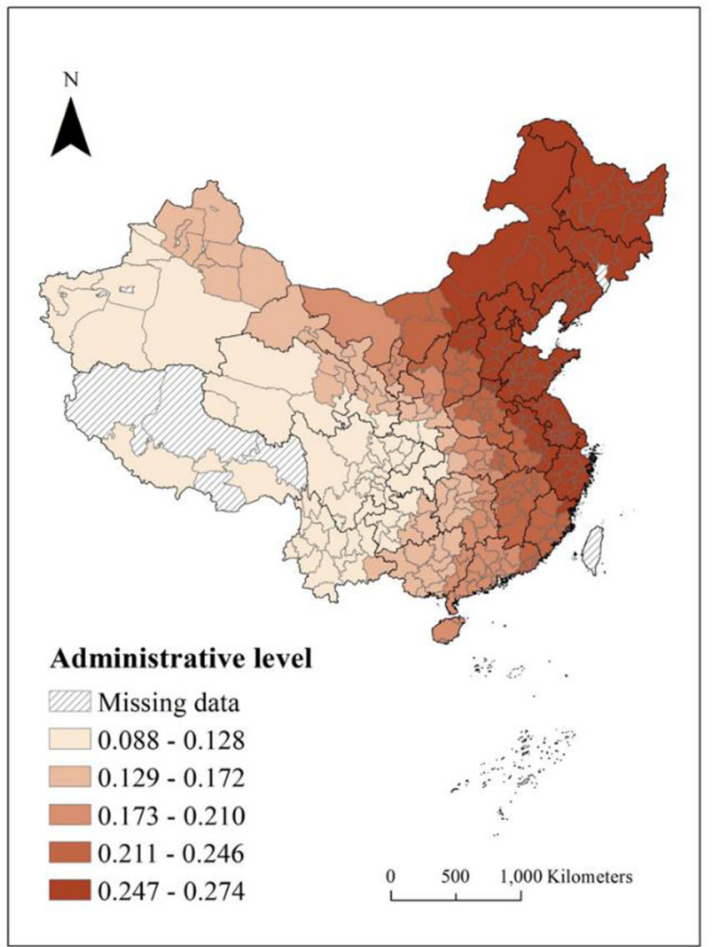

a. Coefficients on SIWH

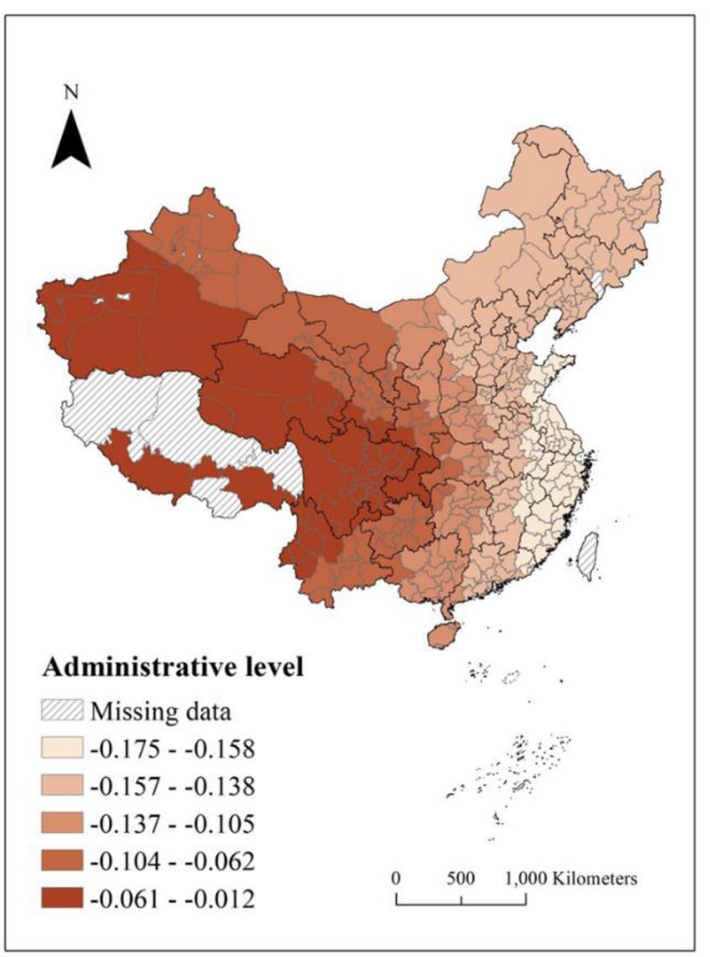

c. Coefficients on SIWOH

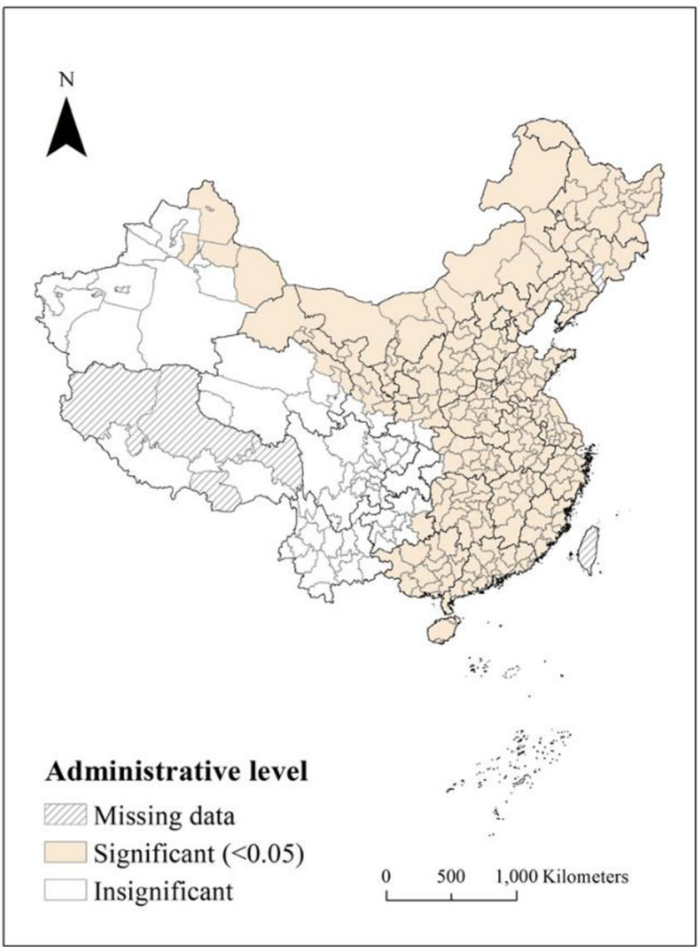

b. Significance of coefficients on SIWH

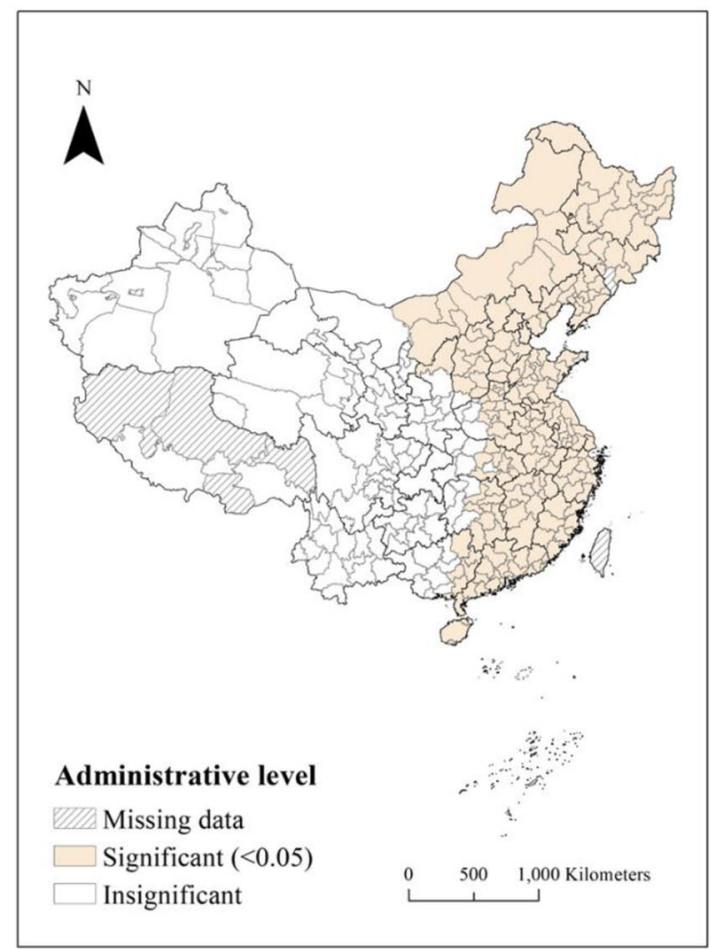

d. Significance of coefficients on SIWOH

Fig. 3 (See legend on next page.) 
(See figure on previous page.)

Fig. 3 The impact of administrative level on SIWH and SIWOH. Notes: SIWH represents the proportion of migrants with settlement intention and willingness of hukou conversion. SIWOH represents the proportion of migrants with settlement intention but without the willingness of hukou conversion. The significance is measured by $p$-value. Significant coefficients are those which pass the significance test at 0.05 level

willingness of hukou conversion). At the administrative dimension, a higher administrative level contributes to a larger proportion of migrants with settlement intention and willingness of hukou conversion in the northeast, eastern, and middle China at the city level. While there is a negative relationship between the administrative level and the proportion of migrants in the $\mathrm{WOH}$ group in the destination. Migrants with settlement intention have a strong incentive to obtain local hukou in the city with a high administrative level while migrants without the willingness of hukou conversion would like to settle in the destination with a low administrative level. At the socio-economic dimension, migrants with settlement intention would like to obtain local hukou in hightier cities. Both administrative level and city tier contribute to an increasing willingness of hukou conversion for migrants with settlement intention in the destination from the western to eastern China. At the environmental dimension, the role of air quality varies among different regions. In southern China, air pollution reduces the willingness of hukou conversion for migrants with settlement intention. While in Xinjiang, cities with higher air quality tend to have a lower proportion of migrants with settlement intention and willingness of hukou conversion.

In China, the value of hukou is tied to the city's administrative hierarchy to some extent. A city with a high administrative level could enjoy more preferential policies and financial support from the central government, which contributes to better social welfare and public services for residents with local hukou in the city. However,

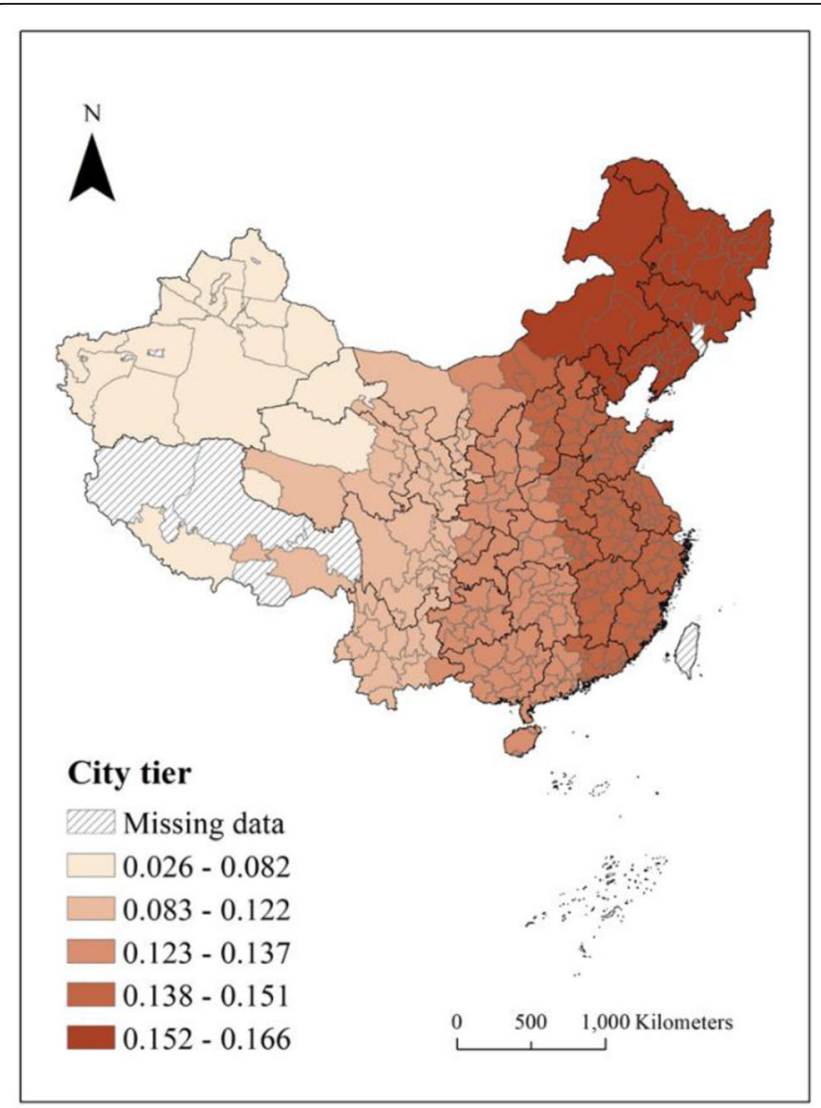

a. Coefficients on SIWH

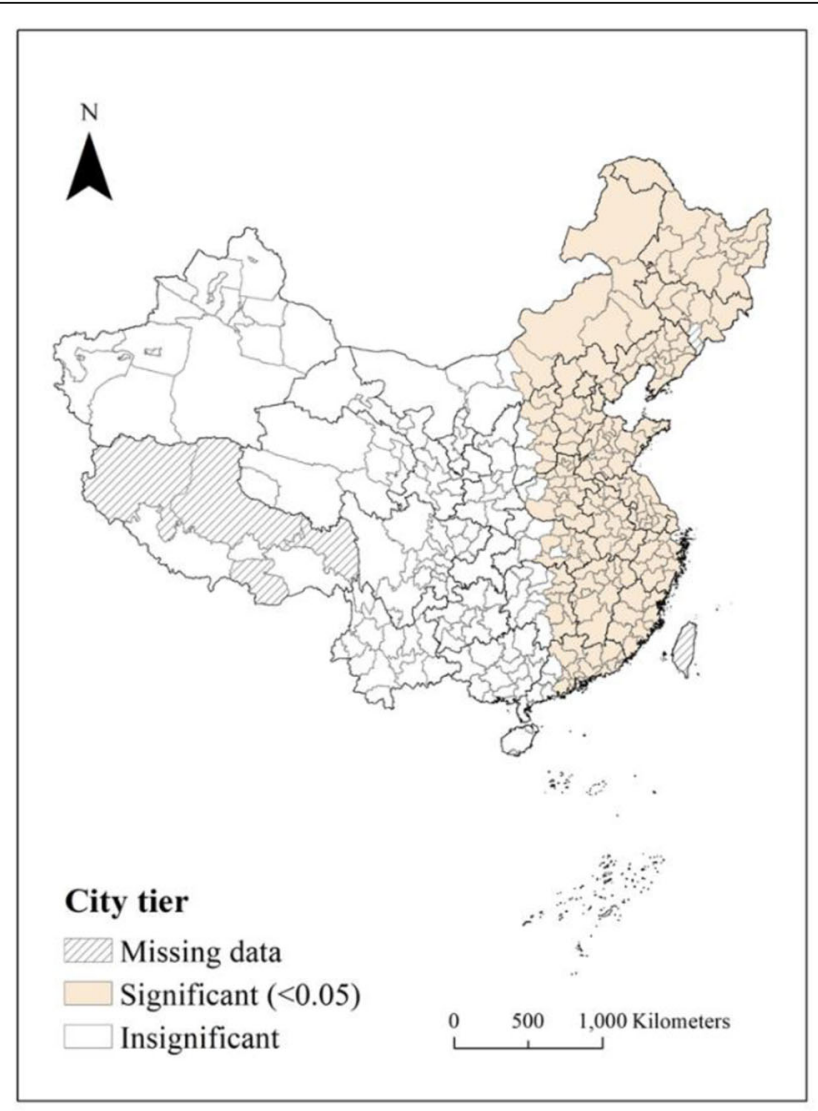

b. Significance of coefficients on SIWH

Fig. 4 The impact of city tier on SIWH. Notes: SIWH represents the proportion of migrants with settlement intention and willingness of hukou conversion. SIWOH represents the proportion of migrants having settlement intention but without the willingness of hukou conversion. The significance is measured by $p$-value. Significant coefficients are those which pass the significance test at 0.05 level 


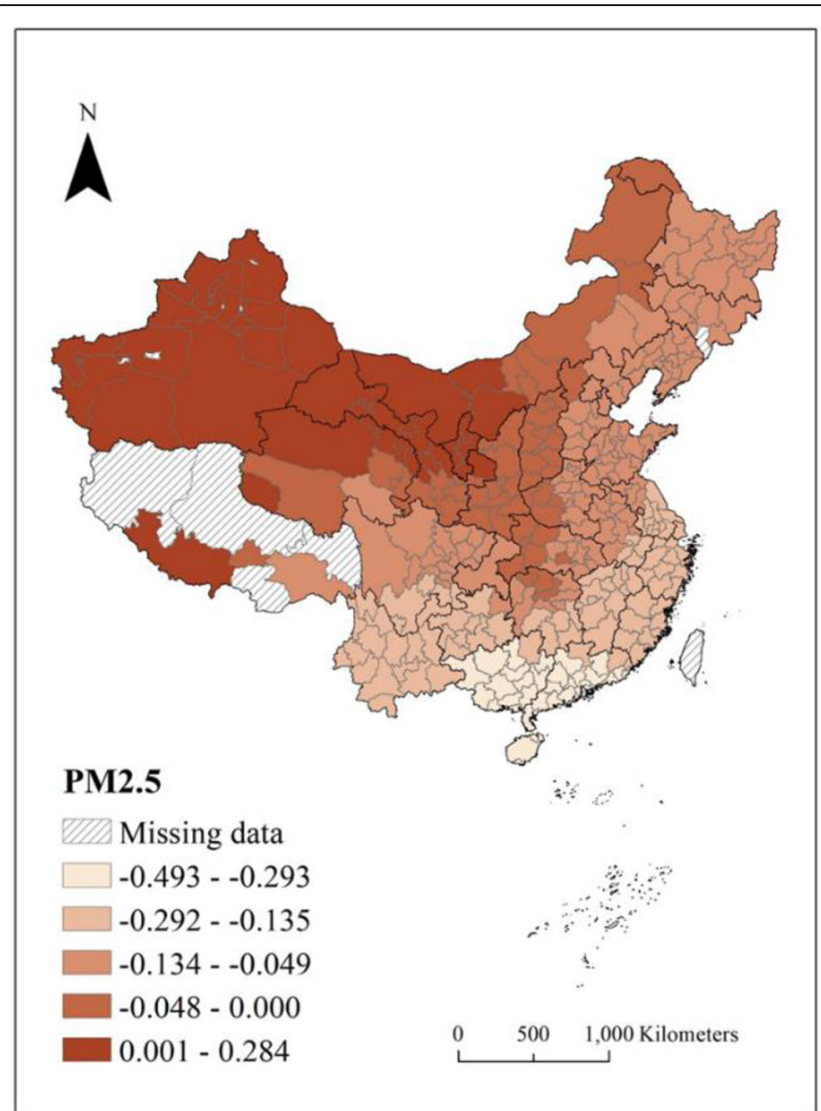

\section{a. Coefficients on SIWH}

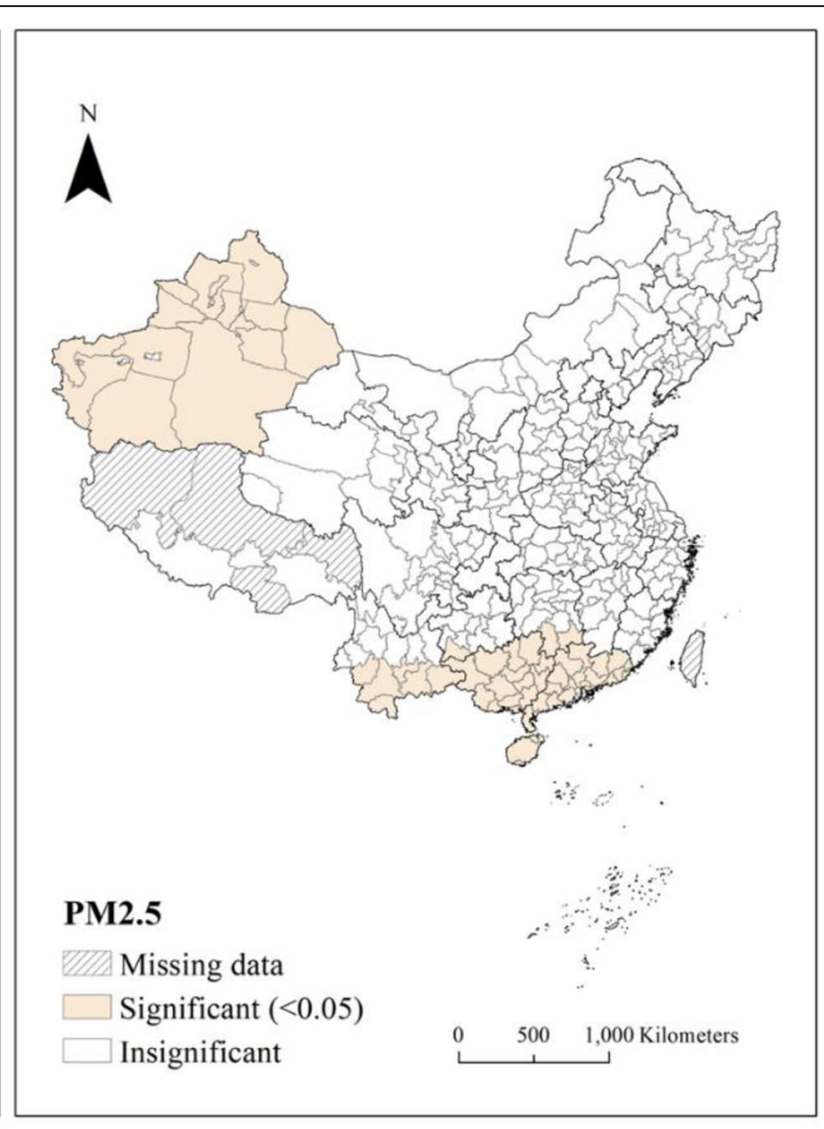

b. Significance of coefficients on SIWH

Fig. 5 The impact of PM 2.5 on SIWH. Notes: SIWH represents the proportion of migrants with settlement intention and willingness of hukou conversion. The significance is measured by $p$-value. Significant coefficients are those which pass the significance test at 0.05 level

migrants' decision to stay or leave is largely determined by employment opportunities and income level (Fan, 2011; Khoo et al., 2008; Zhu, 2007). The economic development level shows a decreasing trend from the eastern to the western China among cities. Even though there are cities with a high administrative level in the western China, the backward economy cannot create enough job opportunities with high income. As a result, the role of administrative level is gradually weakened from the eastern to the western China. Meanwhile, all first-tier cities and most new first-tier/second-tier cities are in the eastern and middle China. Most cities in the western China are in low city tiers with relatively smaller disparities. Thus, the uneven spatial distribution of cities in different city tiers leads to geographically varying impacts of the city tier on migrants' willingness of hukou conversion.

Migrants with settlement intention are more likely to obtain local hukou in destination cities with higher administrative levels and city tier. It is easier to promote urbanization and citizenization in advantaged cities such as Beijing, Shanghai, Guangzhou, and Shenzhen, which have a high administrative level and city tier. In current China, cities with relatively lower administrative levels and city tiers have serious semi-urbanization issues, where migrants only have settlement intention but without the willingness of hukou conversion. How to promote citizenization in these cities should be the focus in the future. Additionally, air quality has a limited impact on the willingness of hukou conversion for migrants with settlement intention. Findings in Xinjiang indicate that clean air with a backward economy cannot attract migrants to work and live in the destination for a long duration. By contrast, cases in southern China suggest that air pollution reduces migrants' willingness to hukou conversion. Indeed, both environmental protection and economic development are important to realize comprehensive urbanization in China.

This research has several limitations. Firstly, the concept of settlement intention varies among different studies. Settlement in the destination permanently or for a long duration is the specific definition of migrants' 
settlement intention usually used in China (Chen \& Fan, 2016; Hao \& Tang, 2015; Li \& Liu, 2019; Liu \& Wang, 2020; Tang \& Hao, 2018). Following previous studies using CMDS data (Gu, Jie, et al., 2020; Gu, Yu, et al., 2020; Liu et al., 2020), settlement intention in this paper refers to migrants who would like to stay for a long duration (more than 5 years) in the destination. A different definition of settlement intention may produce different results. Additionally, our work is conducted at the citylevel, which aims to reveal if the impacts of contextual factors on the willingness of hukou conversion vary geographically. But why migrants with the settlement intention make different decisions on hukou conversion needs further exploration, especially at the individual level. Based on the neoclassical and behavioral perspectives, both rational behavior and bounded rationality need much more attention in future study.

\section{Code availability}

(software application or custom code)

ArcGIS 10.6, MGWR 2.2.

\section{Authors' contributions}

CW and JS designed the study and performed the statistical analysis. YL participated in the design of the study and discussion of the statistical analysis. The author(s) read and approved the final manuscript.

\section{Funding}

The work described in this paper was supported by a Direct Research Grant of The Chinese University of Hong Kong (Project Number 4052229).

Availability of data and materials

Not applicable.

\section{Declaration}

\section{Competing interests}

No conflict of interest exists in the submission of this manuscript.

\section{Author details}

'Department of Geography and Resource Management, The Chinese University of Hong Kong, Shatin, NT, Hong Kong, China. ${ }^{2}$ School of Geography and Planning, Sun Yat-sen University, Guangzhou, China.

Received: 6 January 2021 Accepted: 4 April 2021

Published online: 20 April 2021

\section{References}

Aljandali, A. (2017). Multivariate methods and forecasting with IBM ${ }^{\oplus S P S S}{ }^{\oplus}$ statistics. Springer. https://doi.org/10.1007/978-3-319-56481-4.

Anselin, L. (1995). Local indicators of spatial association-LISA. Geographical Analysis, 27(2), 93-115.

Cai, S., Wang, Y., Zhao, B., Wang, S., Chang, X., \& Hao, J. (2017). The impact of the "air pollution prevention and control action plan" on PM2. 5 concentrations in Jing-Jin-Ji region during 2012-2020. Science of the Total Environment, 580, 197-209. https://doi.org/10.1016/j.scitotenv.2016.11.188.

Chen, C., \& Fan, C. C. (2016). China's hukou puzzle: Why don't rural migrants want urban hukou? The China Review, 16(3), 9-39.

Chen, S., Oliva, P., \& Zhang, P. (2017). The effect of air pollution on migration: Evidence from China (no. w24036). National Bureau of Economic Research.

de Miranda, R. M., de Fatima Andrade, M., Fornaro, A., Astolfo, R., de Andre, P. A., \& Saldiva, P. (2012). Urban air pollution: A representative survey of PM 2.5 mass concentrations in six Brazilian cities. Air Quality, Atmosphere and Health, 5(1), 63-77. https://doi.org/10.1007/s11869-010-0124-1.
Démurger, S., Gurgand, M., Li, S., \& Yue, X. (2009). Migrants as second-class workers in urban China? A decomposition analysis. Journal of Comparative Economics, 37(4), 610-628. https://doi.org/10.1016/j.jce.2009.04.008.

Détang-Dessendre, C., Goffette-Nagot, F., \& Piguet, V. (2008). Life cycle and migration to urban and rural areas: Estimation of a mixed logit model on French data. Journal of Regional Science, 48(4), 789-824. https://doi.org/1 0.1111/j.1467-9787.2008.00571.x.

Fan, C. C. (2001). Migration and labor-market returns in urban China: Results from a recent survey in Guangzhou. Environment and Planning A, 33(3), 479-508. https://doi.org/10.1068/a33150.

Fan, C. C. (2002). The elite, the natives, and the outsiders: Migration and labor market segmentation in urban China. Annals of the Association of American Geographers, 92(1), 103-124. https://doi.org/10.1111/1467-8306.00282.

Fan, C. C. (2007). China on the move: Migration, the state, and the household. Routledge. https://doi.org/10.4324/9780203937372.

Fan, C. C. (2011). Settlement intention and Split households: Findings from a survey of migrants in Beijing's urban villages. The China Review, 11(2), 11-42.

Fotheringham, A. S., Brunsdon, C., \& Charlton, M. (2002). Geographically weighted regression: The analysis of spatially varying relationships. Wiley.

Fotheringham, A. S., Yang, W., \& Kang, W. (2017). Multi-scale geographically weighted regression. Annals of the American Association of Geographers, 107(6), 1247-1265. https://doi.org/10.1080/24694452.2017.1352480.

Fu, Q., \& Ren, Q. (2010). Educational inequality under China's rural-urban divide: The hukou system and return to education. Environment and Planning A, 42(3), 592-610. https://doi.org/10.1068/a42101.

Goodburn, C. (2009). Learning from migrant education: A case study of the schooling of rural migrant children in Beijing. International Journal of Educational Development, 29(5), 495-504. https://doi.org/10.1016/j.ijedudev.2 009.04.005.

Gu, H., Jie, Y., Li, Z., \& Shen, T. (2020). What drives migrants to settle in Chinese cities: A panel data analysis. In Applied Spatial Analysis and Policy. Advance online publication. https://doi.org/10.1007/s12061-020-09358-z.

Gu, H., Yu, H., Sachdeva, M., \& Liu, Y. (2020). Analyzing the distribution of researchers in China: An approach using multiscale geographically weighted regression. In Growth and Change. Advance online publication. https:/doi. org/10.1111/grow.12453.

Guo, F., \& Iredale, R. (2004). The impact of hukou status on migrants' employment: Findings from the 1997 Beijing migrant census. International Migration Review, 38(2), 709-731. https://doi.org/10.1111/j.1747-7379.2004. tb00214.x.

Hao, P., \& Tang, S. (2015). Floating or settling down: The effect of rural landholdings on the settlement intention of rural migrants in urban China. Environment and Planning A, 47(9), 1979-1999. https://doi.org/10.1177/03 $08518 \times 15597131$.

Hao, P., \& Tang, S. (2018). Migration destinations in the urban hierarchy in China: Evidence from Jiangsu. Population, Space and Place, 24(2), e2083.

Kan, H. (2009). Environment and health in China: Challenges and opportunities. Environmental Health Perspectives, 117(12), A530-A531. https://doi.org/10.12 89/ehp.0901615.

Khoo, S. E., Hugo, G., \& McDonald, P. (2008). Which skilled temporary migrants become permanent residents and why? International Migration Review, 42(1), 193-226. https://doi.org/10.1111/j.1747-7379.2007.00118.x.

King, R. (2012). Theories and typologies of migration: an overview and a primer-Willy Brandt Series of Working Papers in International Migration and Ethnic Relations 3/12. Malmö Institute for Studies of Migration, Diversity and Welfare (MIM)-Malmö.

Lao, X, \& Gu, H. (2020). Unveiling various spatial patterns of determinants of hukou transfer intentions in China: A multi-scale geographically weighted regression approach. Growth and Change, 51(4), 1860-1876. https://doi.org/10.1111/grow.12429.

Levinson, A. (2012). Valuing public goods using happiness data: The case of air quality. Journal of Public Economics, 96(9-10), 869-880. https://doi.org/10.101 6/j.jpubeco.2012.06.007.

Li, L., \& Liu, Y. (2019). Understanding the gap between de facto and de jure urbanization in China: A perspective from rural migrants' settlement intention. Population Research and Policy Review, 39(2), 311-338.

Li, S. M., \& Siu, Y. M. (1997). A comparative study of permanent and temporary migration in China: The case of Dongguan and Meizhou, Guangdong Province. International Journal of Population Geography, 3(1), 63-82. https:// doi.org/10.1002/(SICI) 1099-1220(199703)3:1<63:AID-IJPG53>3.0.CO;2-A.

Liang, Z., \& Ma, Z. (2004). China's floating population: New evidence from the 2000 census. Population and Development Review, 30(3), 467-488. https://doi. org/10.1111/j.1728-4457.2004.00024.x. 
Liu, T., \& Wang, J. (2020). Bringing city size in understanding the permanent settlement intention of rural-urban migrants in China. Population, Space and Place, 26(4), e2295.

Liu, X., Cao, G., Liu, T., \& Liu, H. (2016). Semi-urbanization and evolving patterns of urbanization in China: Insights from the 2000 to 2010 national censuses. Journal of Geographical Sciences, 26(11), 1626-1642. https://doi.org/10.1007/ s11442-016-1348-2

Liu, Y., Deng, W., \& Song, X. (2018). Influence factor analysis of migrants' settlement intention: Considering the characteristic of city. Applied Geography, 96, 130-140. https://doi.org/10.1016/j.apgeog.2018.05.014.

Liu, Y., Pan, Z., Liu, Y., Chen, H., \& Li, Z. (2020). Where your heart belongs to shapes how you feel about yourself: Migration, social comparison and subjective well-being in China. Population, Space and Place, 26(7), e2336.

Liu, Y., \& Xu, W. (2017). Destination choices of permanent and temporary migrants in China, 1985-2005. Population, Space and Place, 23(1), e1963.

Lyu, L. C., Liao, Q., \& Huang, R. (2018). Knowledge specialization of cities above the prefecture level in China based on journal articles. Scientia Geographica Sinica, 38(8), 1245-1255

Massey, D. S., Arango, J., Hugo, G., Kouaouci, A., Pellegrino, A., \& Taylor, J. E. (1993). Theories of international migration: A review and appraisal. Population and Development Review, 19(3), 431-466. https://doi.org/10.2307/2938462.

Oshan, T. M., Li, Z., Kang, W., Wolf, L. J., \& Fotheringham, A. S. (2019). Mgwr: A Python implementation of multiscale geographically weighted regression for investigating process spatial heterogeneity and scale. ISPRS International Journal of Geo-Information, 8(6), 269. https://doi.org/10.3390/ijgi8060269.

Qin, Y., \& Zhu, H. (2018). Run away? Air pollution and emigration interests in China. Journal of Population Economics, 37(1), 235-266. https://doi.org/10.1 007/s00148-017-0653-0.

Roberts, K. (2002). Female labor migrants to Shanghai: Temporary "floaters" or potential settlers? International Migration Review, 36(2), 492-519. https://doi. org/10.1111/j.1747-7379.2002.tb00090.x.

Shen, J. (2002). A study of the temporary population in Chinese cities. Habitat International, 26(3), 363-377. https://doi.org/10.1016/S0197-3975(02)00013-9.

Shen, J. (2006). Understanding dual-track urbanisation in post-reform China: Conceptual framework and empirical analysis. Population, Space and Place, 12(6), 497-516. https://doi.org/10.1002/psp.426.

Shen, J. (2018). Urbanization, regional development and governance in China. Routledge. https://doi.org/10.4324/9781315143255.

Sun, C., Kahn, M. E., \& Zheng, S. (2017). Self-protection investment exacerbates air pollution exposure inequality in urban China. Ecological Economics, 131, 468474. https://doi.org/10.1016/j.ecolecon.2016.06.030.

Sun, M., \& Fan, C. C. (2011). China's permanent and temporary migrants: Differentials and changes, 1990-2000. The Professional Geographer, 63(1), 92112. https://doi.org/10.1080/00330124.2010.533562.

Tang, S., \& Hao, P. (2018). Floaters, settlers, and returnees: Settlement intention and hukou conversion of China's rural migrants. The China Review, 18(1), 11-34.

Tsai, I. C., \& Chiang, S. H. (2019). Exuberance and spillovers in housing markets: Evidence from first-and second-tier cities in China. Regional Science and Urban Economics, 77, 75-86. https://doi.org/10.1016/j.regsciurbeco.2019.02.005.

Wang, C. L., Liu, H., \& Zhang, M. T. (2020). Exploring the mechanism of border effect on urban land expansion: A case study of Beijing-Tianjin-Hebei region in China. Land Use Policy, 92, 104424. https://doi.org/10.1016/j.landusepol.201 9.104424

Wang, C. L., Liu, H., Zhang, M. T., et al. (2018). The border effect on urban land expansion in China: The case of Beijing-Tianjin-Hebei region. Land Use Policy, 78, 287-294. https://doi.org/10.1016/j.landusepol.2018.06.050.

Wang, W. W., \& Fan, C. C. (2012). Migrant workers' integration in urban China: Experiences in employment, social adaptation, and self-identity. Eurasian Geography and Economics, 53(6), 731-749. https://doi.org/10.2747/1539-7216. 53.6.731.

Wellenius, G. A., Burger, M. R., Coull, B. A., Schwartz, J., Suh, H. H., Koutrakis, P., Schlaug, G., Gold, D. R., \& Mittleman, M. A. (2012). Ambient air pollution and the risk of acute ischemic stroke. Archives of Internal Medicine, 172(3), 229234. https://doi.org/10.1001/archinternmed.2011.732.

Wu, L., \& Bian, Y. (2018). Housing, consumption and monetary policy: How different are the first-, second-and third-tier cities in China? Applied Economics Letters, 25(15), 1107-1111. https://doi.org/10.1080/13504851.201 7.1412069 .

Wu, Q., Zhang, X., Xu, Y., \& Li, T. (2016). Dualities of semi-urbanization villages in social-spatial transition: A case study of Zhoucun village in suburban Nanjing,
China. Journal of Rural Studies, 47, 657-664. https://doi.org/10.1016/j.jrurstud.2 016.06.007.

Zhang, W., Zhou, Y. Y., \& Hu, G. W. (2013). Coupling mechanism and space-time coordination of new-approach urbanization, new-approach industrialization and service industry modernization in megacity behemoths: A case study of ten cities in China. Scientia Geographica Sinica, 33(5), 562-569.

Zhang, X., Zhang, X., \& Chen, X. (2017). Happiness in the air: How does a dirty sky affect mental health and subjective well-being? Journal of Environmental Economics and Management, 85, 81-94. https://doi.org/10.1016/j.jeem.2017. 04.001.

Zhang, X. C., \& Sun, Y. (2019). Investigating institutional integration in the contexts of Chinese city-regionalization: Evidence from ShenzhenDongguan-Huizhou. Land Use Policy, 88, 104170. https://doi.org/10.1016/j.la ndusepol.2019.104170.

Zhu, Y. (2007). China's floating population and their settlement intention in the cities: Beyond the Hukou reform. Habitat International, 31(1), 65-76. https:// doi.org/10.1016/j.habitatint.2006.04.002.

Zhu, Y., \& Chen, W. (2010). The settlement intention of China's floating population in the cities: Recent changes and multifaceted individual-level determinants. Population, Space and Place, 16(4), 253-267.

Zhu, Y., \& Lin, L. (2014). Continuity and change in the transition from the first to the second generation of migrants in China: Insights from a survey in Fujian. Habitat International, 42, 147-154. https://doi.org/10.1016/j.habitatint.2013.12. 002.

\section{Publisher's Note}

Springer Nature remains neutral with regard to jurisdictional claims in published maps and institutional affiliations. 